\title{
Role of semi-quantitative bacteriological culture in management of chronic wound infections
}

\author{
R Vanaja ${ }^{1}$, S. Geetha Banu',* \\ ${ }^{1}$ Professor, Institute of Microbiology, Madras Medical College, Chennai, Tamil Nadu, \\ ${ }^{2}$ Assistant Professor, Dept. of Microbiology, Meenakshi Ammal Dental College, Chennai, Tamil Nadu, India
}

*Corresponding Author:

Email: ggthabasya@gmail.com

Received: $26^{\text {th }}$ June, 2018

Accepted: $13^{\text {th }}$ July, 2018

\begin{abstract}
Introduction: The role of quantitative microbiology in the management of wound infections is very crucial. In this study semiquantitative swab technique is used as a simple procedure for assessing the bacterial load of chronic non healing wounds, thereby distinguishing the patients with infected ulcers from colonized one, thereby restricting the use of antibiotics only to the appropriate infected population.

Aim: To assess the role of semi-quantitative bacterial culture of chronic non healing wounds in differentiating between colonised and infected wounds based on bacterial load.

Setting and Design: This is a cross sectional study carried out in the Department of Microbiology in a tertiary care government medical College.

Materials and Methods: Two wound swabs were taken using sterile cotton swabs from 100 patients with chronic non healing ulcer wounds. Semi-quantitative aerobic bacterial culture was done.

Results: Among 100 patients for whom semi-quantitative culture was done, 72 patients showed growth, of which 21 patients had poly-microbial growth making a total of 93 isolates. Out of the total 93 isolates, 73 isolates had a significant count of $\geq 3+$, hence considered as pathogens. The most commonly isolated pathogens were Staphylococcus aureus (24.6\%) and Pseudomonas aeruginosa (24.6\%). 55.5\% were Methicillin resistant Staphylococcus aureus (MRSA). 65\% of Enterobacteriaceae were ESBL producers and $15 \%$ were AmpC $\beta$-lactamase producers.

Conclusion: This study emphasizes the importance and benefits of semi-quantitative bacterial culture technique in differentiating between pathogens and colonisers and enable refinement of antibiotic regimens and thereby curbing antibiotic resistance.
\end{abstract}

Keywords: Chronic ulcers, Semi-quantitative culture, Bacterial load, Antibiotic resistance, ESBL, MRSA.

\section{Introduction}

Chronic non healing wounds pose a significant burden to healthcare systems and also cause morbidity and mortality to patients. In India, the estimate of patients suffering from chronic wounds is around 2.8 million per year and the treatment cost accounts to billions of rupees. A community based epidemiological study of wounds conducted in India, estimated the prevalence rate of chronic wounds to be 4.5 per 1000 population. ${ }^{1}$

Wound healing is a complex series of events that should have the capacity to overcome the obstacles and eventually result in wound closure. There are many factors that impede or prevent wound healing. One of the most serious extrinsic factors affecting wound healing is infection.

The quantitative definition of infection has defined as the presence of $10^{5}$ colony forming units per square centimetre or gram of tissue. ${ }^{2}$ It is reported that healing of ulcers were delayed when the bacterial load was more than $10^{6} \mathrm{CFU} / \mathrm{ml}$ of wound. ${ }^{3,4}$ Considering the concept of critical colonisation, ${ }^{4}$ it is reported that a critical level of bacteria of more than or equal to $10^{4} \mathrm{CFU} / \mathrm{g}$ of tissue should be achieved to cause wound infection. Hence the role of quantitative microbiology in the management of wound infections as suggested by many studies, is very crucial, as it can predict the risk of wound infection and the capacity of wound healing.

Nevertheless, since quantification of bacteria by obtaining tissue biopsy is an invasive procedure, noninvasive techniques such as the semi-quantitative swab can be used to obtain reliable information on the bacterial load. And thus can assist the clinicians in differentiating between colonised and infected wounds.

Hence in this study semi-quantitative swab technique was used as a simple procedure for assessing the bacterial profile of wounds that are clinically infected or having a delayed wound healing, thereby distinguishing the patients with infected ulcers from colonized one. This would help the clinicians in the management of chronic wounds and also prevent inadvertent use of antibiotics and restricting the use only to the appropriate infected population.

\section{Materials and Methods}

This is aCross sectional studycarried out in the Department of Microbiology in a tertiary care government medical College, from September 2015 to February 2016. 100 patientswith chronic non healing ulcer wounds were included in the study.

Two wound swabs were taken using sterile cotton swabs by Levine's technique. ${ }^{5}$ The wound was cleaned 
thoroughly with sterile saline and all superficial exudates removed. A $1-\mathrm{cm}^{2}$ area of tissue around the centre of the wound base is sampled using sterile cotton swab for 5 seconds with sufficient pressure to express fluid from within the wound tissue. Direct Gram staining was done with one of the swabs and interpreted as per standard guidelines. The other swab was rolled over an area of $2 \mathrm{~cm}$ diameter on the first quadrant of the blood agar plate followed by dilution streaking technique in the other 3 quadrants ${ }^{6}$ and also plated onto MacConkey agar plate. Plates were incubated for 18 to 24 hours at $37{ }^{\circ} \mathrm{C}$ under aerobic conditions. After 18 to 24 hours of incubation, MacConkey agar and Blood agar plates were observed for growth, colony count and colony morphology. Semiquantisation of bacterial colonies was done according to the grading procedure based on the number of colonies in each quadrant. ${ }^{6}$

Semi-quantitative grading procedure for bacterial isolates on growth media: ${ }^{6}$

\begin{tabular}{|l|c|c|c|c|}
\hline \multirow{2}{*}{ Score } & \multicolumn{4}{|c|}{ Number of colonies visible in each quadrant } \\
\cline { 2 - 5 } & 1st Quadrant & 2nd Quadrant & 3rd Quadrant & 4th Quadrant \\
\hline $1+$ & $<10$ & & & \\
\hline $2+$ & $<10$ & $<10$ & $>10$ & \\
\hline $3+$ & $>10$ & $>10$ & $>10$ & $>5$ \\
\hline $4+$ & $>10$ & $>10$ & & \\
\hline
\end{tabular}

In the present study, grading of $3+$ and $4+$ are considered as pathogens causing infection and grading $\leq$ $2+$ are considered as either contaminants or colonisers. ${ }^{7}$ Antibiotic sensitivity testing of the pathogens and their resistance pattern was done as per CLSI document $\mathrm{M}$ $100-\mathrm{S} 26{ }^{8}$

\section{Results}

The results were analyzed statistically using SPSS version 17.0. In our study the age of the patients ranged from 18 to 75 years. The mean and Standard deviation of age (in years) of patients were 46.1 and 14.364 respectively. Majority of the patients were in the age group of 31-60 years. Out of 100 patients 77 were males and 23 were females. Majority of the patients had venous ulcers $(56 \%)$, followed by diabetic ulcers $(22 \%)$.

Out of 100 patients for whom semi-quantitative culture was done, 72 patients showed growth and 28 patients had no growth in culture (Table 1). Of the 72 patients who showed growth, 21 patients had polymicrobial growth making a total of 93 isolates. Out of the total 93 isolates, 73 isolates had a significant count of $\geq 3+$, hence considered as pathogens and 20 isolates had semi-quantitative bacterial grading of $2+$ and hence considered as either colonisers or contaminants (Table $2)$. The most commonly isolated pathogens in semiquantitative culture were Staphylococcus aureus (24.6\%) and Pseudomonas aeruginosa (24.6\%) (Table 3).
The antibiotic susceptibility pattern of the Staphylococcus aureus in the present study, showed that the isolates were sensitive to Gentamicin (55.5\%), Ciprofloxacin $(55.5 \%)$, Tetracycline $(88.8 \%)$ and least sensitive to Penicillin (22.2\%), Cotrimoxazole (33.3\%) and Erythromycin (44.4\%). Enterobacteriaceae isolates in the present study, were sensitive to Ciprofloxacin (64\%), Tetracycline (72\%), Gentamicin (60\%), and least susceptible to Cefotaxime $32 \%$ ) and Cotrimoxazole (24\%). All Enterobacteriaceae were highly susceptible to Imipenem (100\%). Pseudomonas aeruginosa in the present study, were sensitive to Ceftazidime (55.5\%), Gentamicin (44.4\%), and Ciprofloxacin (33.3\%). Acinetobacter were sensitive to Ciprofloxacin (33.3\%) and Cotimoxazole (33.3\%) All isolates of Pseudomonas aeruginosa and Acinetobacter were highly susceptible to Imipenem (100\%) and Piperacillin-Tazobactam (100\%).

Out of 18 Staphylococcus aureus isolates, 10 (55.5\%) were Methicillin resistant Staphylococcus aureus (MRSA) (Table 4). All the MRSA isolates (10) were susceptible to Vancomycin tested by determination of Minimum Inhibitory concentration by Macro broth dilution method. Out of the isolates tested for ESBL production 15 isolates $(65 \%)$ were found to be ESBL producers and $8(15 \%)$ were AmpC $\beta$-lactamases producers. Test for MBL and carbapenamases production was not done as all Gram negative bacilli isolates were sensitive to Imipenem (Table 5).

Table 1: Interpretation of semi-quantitative culture results $n=100$

\begin{tabular}{|l|c|c|c|}
\hline Semi-quantitative culture & Bacterial grading & No of isolates & \multirow{2}{*}{ No of patients } \\
\cline { 2 - 3 } Growth & $4+$ & 32 & \multirow{2}{*}{} \\
\hline & $3+$ & 41 & 72 \\
\hline No growth & $2+$ & 20 & 28 \\
\hline Total & - & - & 100 \\
\hline
\end{tabular}


Table 2: Categorisation of ulcers based on semi-quantitative bacterial culture

\begin{tabular}{|l|c|c|c|}
\hline Semi-quantitative culture & Bacterial grading & No of isolates & \multirow{2}{*}{ Total } \\
\cline { 2 - 3 } Pathogens & $4+$ & 32 & 73 \\
\hline Colonisers & $3+$ & 41 & 20 \\
\hline Total & $2+$ & 20 & 93 \\
\hline
\end{tabular}

Table 3: Bacteriological Profile of semi-quantitative bacterial culture $\mathbf{n = 9 3}$

\begin{tabular}{|c|c|c|c|c|}
\hline Type of isolate & Organism & $\begin{array}{l}\text { Total no of } \\
\text { pathogens }\end{array}$ & $\begin{array}{l}\text { Total no of } \\
\text { colonisers }\end{array}$ & Total \\
\hline $\begin{array}{l}\text { Gram positive } \\
\text { cocci }\end{array}$ & Staphylococcus aureus & $\begin{array}{c}18 \\
(24.6 \%)\end{array}$ & $\begin{array}{c}6 \\
(30 \%)\end{array}$ & $\begin{array}{c}24 \\
(25 \%)\end{array}$ \\
\hline \multirow[t]{9}{*}{$\begin{array}{l}\text { Gram negative } \\
\text { bacilli }\end{array}$} & Pseudomonas aeruginosa & $\begin{array}{c}18 \\
(24.6 \%) \\
\end{array}$ & $\begin{array}{c}5 \\
(25 \%)\end{array}$ & $\begin{array}{c}23 \\
(24.7 \%)\end{array}$ \\
\hline & Pseudomonas species & $\begin{array}{c}6 \\
(8.2 \%)\end{array}$ & - & $\begin{array}{c}6 \\
(6.4 \%)\end{array}$ \\
\hline & Klebsiella pneumonia & $\begin{array}{c}7 \\
(9.5 \%)\end{array}$ & $\begin{array}{c}2 \\
(10 \%)\end{array}$ & $\begin{array}{c}9 \\
(9.7 \%)\end{array}$ \\
\hline & Klebsiellaoxytoca & $\begin{array}{c}6 \\
(8.2 \%)\end{array}$ & $\begin{array}{c}1 \\
(5 \%)\end{array}$ & $\begin{array}{c}7 \\
(7.5 \%)\end{array}$ \\
\hline & Acinetobacter baumannii & $\begin{array}{c}6 \\
(8.2 \%)\end{array}$ & - & $\begin{array}{c}6 \\
(6.4 \%)\end{array}$ \\
\hline & Escherichia coli & $\begin{array}{c}5 \\
(7 \%) \\
\end{array}$ & $\begin{array}{c}3 \\
(15 \%)\end{array}$ & $\begin{array}{c}8 \\
(8.6 \%)\end{array}$ \\
\hline & Proteus mirabilis & $\begin{array}{c}5 \\
(7 \%)\end{array}$ & $\begin{array}{c}2 \\
(10 \%)\end{array}$ & $\begin{array}{c}7 \\
(7.5 \%)\end{array}$ \\
\hline & Proteus vulgaris & $\begin{array}{c}2 \\
(2.7 \%)\end{array}$ & $\begin{array}{c}1 \\
(5 \%)\end{array}$ & $\begin{array}{c}3 \\
(3.2 \%)\end{array}$ \\
\hline & Total & $\begin{array}{c}73 \\
(100 \%)\end{array}$ & $\begin{array}{c}20 \\
(100 \%)\end{array}$ & $\begin{array}{c}93 \\
(100 \%)\end{array}$ \\
\hline
\end{tabular}

Table 4: Methicillin resistance among Staphylococcus aureus isolates by cefoxitin screening method (n=18)

\begin{tabular}{|l|c|c|c|}
\hline \multicolumn{1}{|c|}{ Gram positive cocci } & Resistance pattern & Number of isolates & Percentage \\
\hline \multirow{2}{*}{$\begin{array}{l}\text { Staphylococcus aureus } \\
\mathrm{n}=18\end{array}$} & MRSA & 10 & $55.5 \%$ \\
\cline { 2 - 4 } & MSSA & 8 & $44.4 \%$ \\
\hline
\end{tabular}

Table 5: Distribution of resistance pattern in Gram negative bacilli

\begin{tabular}{|l|c|c|c|c|}
\hline \multirow{2}{*}{ Gram Negative Bacilli $(\mathbf{n}=55)$} & \multicolumn{2}{c|}{$\begin{array}{c}\text { Extended-Spectrum Beta } \\
\text { Lactamases (ESBL) }\end{array}$} & \multicolumn{2}{c|}{ AmpC Beta-lactamases } \\
\cline { 2 - 5 } & $\mathbf{N}$ & $\mathbf{\%}$ & $\mathbf{N}$ & $\%$ \\
\hline Escherichia coli $(\mathrm{n}=5)$ & 3 & 60 & 0 & 0 \\
\hline Klebsiella oxytoca $(\mathrm{n}=6)$ & 4 & 66.6 & 2 & 3.3 \\
\hline Klebsiella pneumonia $(\mathrm{n}=7)$ & 4 & 57.1 & 1 & 25 \\
\hline Proteus vulgaris $(n=2)$ & - & - & 0 & 0 \\
\hline Proteus mirabilis $(n=5)$ & 4 & 80 & 0 & 0 \\
\hline Pseudomonas aeruginosa $(\mathrm{n}=18)$ & - & - & 3 & 16.6 \\
\hline $\begin{array}{l}\text { Pseudomonas species } \\
(\text { n=6) }\end{array}$ & - & - & 0 & 0 \\
\hline Acinetobacter baumanii $(n=6)$ & - & - & 2 & 3.3 \\
\hline Total & 15 & & 8 & \\
\hline
\end{tabular}




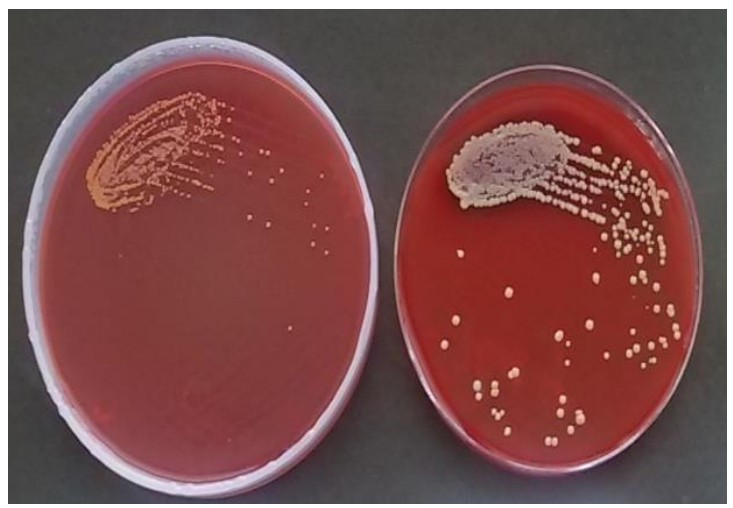

Fig. 1: Semi-quantitative culture method

\section{Discussion}

Wounds or ulcers are classified as acute or chronic according to the duration they have persisted. However, there is no specific length of time to define chronicity. ${ }^{9}$ Chronic wounds or ulcers come with significant morbidity and cost for the patients and society as a whole. This study was carried out to assess the role of semi-quantitative bacterial culture in differentiating between pathogens and colonisers in chronic wounds thereby aid in the management.

In this study, out of 100 study population, 77 were males and 23 were females. Majority of the patients $(25 \%)$ were in the age group of 51 to 60 years. According to many studies, it was stated that chroniclegulcers affect $0.6-3 \%$ of patients aged over 60 years, increasing to over $5 \%$ of those aged over 80 years. The incidence of ulceration is also rising as a result of aging population and increased risk factors for atherosclerotic occlusion such as smoking, obesity and diabetes. ${ }^{10}$

In our study majority of the patients had venous ulcers $(56 \%)$, followed by diabetic ulcers $(22 \%)$. This is similar to studies from India that show that etiology of chronic wounds include causes like venous hypertension, arterial insufficiency, neuropathy like diabetes, pressure ulcers, vasculitis or trauma. ${ }^{10,11}$ In another study it had been reported that ulcers related to venous insufficiency constitute $70 \%$, arterial disease $10 \%$, and most of the others are due to either neuropathy (usually diabetic) or a combination of those diseases. ${ }^{6}$

Semi-quantitative Swab Culture: In our present study, 2 wound swabs were taken by Levine's technique from patients with chronic non healing ulcers and semiquantitation of bacterial colonies were done according to the grading procedure based on the number of colonies in each quadrant. Out of 100 patients with chronic non healing ulcers, 72 patients showed growth and 28 patients had no growth in culture (Table 1). Of the 72 patients who showed growth, 21 patients had polymicrobial growth making a total of 93 isolates.

The interaction between the Wounds and Bacteria can be classified into four Levels: Contamination, colonization, critical colonization and infection. The line to differentiate between colonization and infection had always been difficult to define. The term 'critical colonization' has been used to describe the stage at which bacteria begin to adversely affect wound healing. ${ }^{14} \mathrm{~A}$ critical threshold of $10^{5}$ bacteria has been proposed as the delineation between colonization and a clinically relevant infection that may impede wound healing. . $^{15,16}$

A correlation between semi-quantitative swab data and quantitative biopsy data has been reported in many studies. ${ }^{7,17,18}$ In semi-quantitative swab technique, 1+ growth correlates with a bacterial count of $10^{2}$ to $10^{3}$ $\mathrm{CFU} / \mathrm{g}$ and $4+$ correlates with a bacterial count of approximately $10^{7} \mathrm{CFU} / \mathrm{g} .{ }^{71}{ }^{17} \mathrm{Swabs}$ that yield more than 30 CFU indicate a tissue count of $10^{5} \mathrm{CFU} / \mathrm{g} .{ }^{7,18}$ According to studies semi-quantitative count of $\geq 3+$ was considered significant. ${ }^{7}$

Hence in our study grading of $3+$ and $4+$ are considered as significant growth causing infection and grade with $1+\& 2+$ are considered either as contaminants or colonisers. In our study out of 93 isolates, 73 isolates had a significant count of $\geq 3+$, hence considered as pathogens. 20 isolates had semiquantitative bacterial grading of $2+$ and hence considered as colonisers or contaminants (Table 2).

Thus from the present study, the superficial swab sampling procedure becomes the simple, inexpensive, non-invasive and convenient method than a quantitative biopsy. From a quantitative perspective, this method is beneficial in providing a semi-quantitative estimation of the microbial load and thereby differentiating between pathogens and colonisers or contaminants and also determining the optimal time point for antibiotic treatment. From a qualitative perspective, this method provides the profile of causative bacteria.

Aerobic Bacteriological Profile of Chronic Wounds and their Antibiotic Resistance Pattern: In our study the predominant pathogens isolated by semiquantitative culture were Staphylococcus aureus (24.6\%) and Pseudomonas aeruginosa $(24.6 \%) \%$ (Table $3)$. The other isolates were Klebsiella pneumonia $(9.5 \%)$, Klebsiellaoxytoca (8.2\%), Escherichia coli (7\%), Proteus mirabilis (7\%), Proteus vulgaris $(2.7 \%)$, and Acinetobacter baumanii (8.2\%). Six Pseudomonas species $(8.2 \%)$ were isolated out of which 2 was Pseudomonas fluorescens, and 4 were Pseudomonas putida.

This is similar to the study conducted by Bowler et al, in which Staphylococcus aureus is reported to be the common bacterium isolated in traumatic ulcers, surgical site infections and burns ulcers. ${ }^{7}$ In review article by R. S. Howell-Jones et al, Staphylococcus aureus has been reported in frequencies varying from $43 \%$ of infected leg ulcers. ${ }^{14}$ Pseudomonas aeruginosa is another frequently identified organism and has been found in $7-33 \%$ of ulcers. A number of other aerobic species have also been reported, including Escherichia coli, Klebsiella species and Proteus species. ${ }^{14,21}$

There are many studies which have investigated the role of microorganisms in wound healing. These studies 
have shown that the primary pathogens that cause delayed wound healing and infection are Staphylococus aureus, Pseudomonas aeruginosa, and beta-hemolytic Streptococci as they are notorious for their capacity to produce dangerous destructive virulence factors. ${ }^{719}$ Due to the chronicity of the wound, Methicillin Resistant Staphylococcus aureus (MRSA) like organisms may colonise the wound and cause wound infection ${ }^{(20)}$ which is the most common pathogen in our study too.

Antibiotics are frequently used in the management of chronic wounds and these patients receive significantly more antibiotic prescriptions both as systemic and topical application. Antibiotic resistance in bacteria has thus become a concerning issue and the control of infections is extremely difficult. As a result, there has been a great interest to detect antibiotic resistance of the causative bacteria. ${ }^{14}$

The antibiotic susceptibility pattern of the Staphylococcus aureus in the present study, showed that the isolates were sensitive to Penicillin (22.2\%), Erythromycin (44.4\%), Gentamicin (55.5\%), Ciprofloxacin (55.5\%), and Tetracycline (88.8\%). Enterobacteriaceae isolates in the present study, were sensitive to Ciprofloxacin (64\%), Tetracycline (72\%), Gentamicin $(60 \%)$, and least susceptible to Cefotaxime (32\%), Cotrimoxazole (24\%). All Enterobacteriaceae were highly susceptible to Imipenem (100\%). Pseudomonas aeruginosa in the present study, were sensitive to Ceftazidime (55.5\%), Gentamicin (44.4\%), and Ciprofloxacin (33.3\%). Acinetobacter was sensitive to Ciprofloxacin (33.3\%) and Cotimoxazole (33.3\%) All isolates of Pseudomonas aeruginosa and Acinetobacter were highly susceptible to Imipenem (100\%) and Piperacillin-Tazobactam (100\%).

In the present study out of 18 Staphylococcus aureus isolates, $10(55.5 \%)$ were Methicillin resistant Staphylococcus aureus (MRSA) (Table 4). All the MRSA isolates (10) were susceptible to Vancomycin tested by determination of Minimum Inhibitory concentration by Macro broth dilution method. Out of the isolates tested, 15 isolates $(65 \%)$ were found to be ESBL producers and $8(15 \%)$ were AmpC $\beta$-lactamases producers. Test for MBL resistance and carbapenamase production was not done as all Gram negative bacilli isolates were sensitive to Imipenem (Table 5).

The above antimicrobial susceptibility pattern in this study is similar to many studies conducted to analyse the incidence of antimicrobial resistance of bacterial isolates causing wound infection and delayed wound healing.

According to Frankel et al, ${ }^{22}$ the incidence of MRSA was $45 \%$ among patients with chronic wounds. Colsky et $\mathrm{al}^{23}$ found $50 \%$ of Staphylococcus aureus isolates from hospitalized patients with leg ulcers to be MRSA. A study by Tentolouris et $\mathrm{al}^{24}$ in a diabetic foot clinic, found $40 \%$ of Staphylococcus aureus isolated from patients with infected foot ulcers to be MRSA. But in another study ${ }^{25}$ it was found that only $12 \%$ of
Staphylococcus aureus to be MRSA in infected diabetic ulcer foot. They have also found high levels of resistance to erythromycin in Staphylococcusaureus.

In study conducted by Nyambura Moremi et $a 1,{ }^{26}$ $41 \%$ were ESBL producers among the Enterobacteriaceae isolates. Mathur et $\mathrm{a}^{27,28}$ found out that $68.0 \%$ of Enterobacteriaceae were ESBL producers, whereas Kumar et al ${ }^{27,29}$ reported only $19.2 \%$ of E. coli isolates as ESBL producers. The resistance pattern of isolates in our study is also similar to the study conducted by Umadevi et al ${ }^{27,30}$ in which $65.5 \%$ of $S$ aureus were MRSA positive and $56 \%$ of Enterobacteriaceae were ESBL producers, among which $62.5 \%$ of Proteus species, $60 \%$ of Klebsiella pneumonia and $56 \%$ of Escherichia coli were ESBL producers. It was also found that Amikacin, Piperacillin-tazobactam, Imipenem were sensitive against gram-negative bacilli, while Vancomycin was sensitive against gram-positive bacteria.

In the study by Citron et $\mathrm{al}^{27,31}$ all aerobic grampositive organisms were susceptible to vancomycin like in our study and also Pseudomonas aeruginosa strains and the Enterobacteriaceae group were also largely susceptible to imipenem, piperacillin-tazobactam. The isolates were least susceptible to amoxicillinclavulanate, doxycycline, and cephalexin. The study by Murugan et $\mathrm{al}^{27,32}$ also showed that $E$. coli exhibited $100 \%$ susceptibility to imipenem and meropenem and resistant to cephalexin, erythromycin, gentamycin. An Indian study on soft tissue infections documented $72.37 \%$ ESBL producers among E. coli. It was found that $36 \%$ of Gram negative bacilli were ESBL producers and AmpC was seen among enteric GNB (10\%) and Acinetobacter species (18\%). ${ }^{33}$

\section{Conclusion}

Quantitative bacterial cultures become essential part of management of chronic wounds. According to our study semi quantitative bacterial culture using superficial swab technique can be used as a simple procedure for assessing the bacterial load and the bacterial flora of wounds that are clinically infected or having a delayed wound healing, thereby differentiate between pathogens and colonisers. Semi-quantitative swabs are thus beneficial for clinicians who want to adjust their wound care based on bacterial bio-burden and thus prevent inadvertent use of antibiotics causing increased antibiotic resistance.

\section{References}

1. Gupta N, Gupta SK, Shukla VK, Singh SP. An Indian community-based epidemiological study of wounds. $J$ Wound Care. 2004;13(8): 323-5.

2. Terry Swanson, David Keast, Rose Cooper, Joyce Black, Donna Angel, Greg Schultz, Keryln Carville, Jacqui Fletcher. Ten top tips: identification of wound infection in a chronic wound. Wounds International 2015;6(2).

3. Bendy, R. H., P. A. Nuccio, E. Wolfe, B. Collins, C. Tamburro, W. Glass, and C. M. Martin. Relationship of 
quantitative wound bacterial counts to healing of decubiti. Effect of topical gentamicin. Antimicrob. Agents Chemother. 1964;10:147-55.

4. Breidenbach, W. C., S. Trager. Quantitative culture technique and infection in complex wounds of the extremities closed with free flaps. Plast Reconstr Surg. 1995(5):860-65.

5. Paul Drinka, Phyllis Bonham, Christopher J. Crnich. Controversies in Long Term Care Swab Culture of Purulent Skin Infection to Detect Infection or Colonization with Antibiotic-Resistant Bacteria. JAMDA. 2012;(1):75-9.

6. Patricia M. Tille. Bailey and Scott's Diagnostic Microbiology, 13 ed. USA:2014.

7. P. G. Bowler, B. I. Duerden, D. G. Armstrong. Wound microbiology and associated approaches to wound management. Clin Microbiol Rev. 2001;14(2):244-69.

8. Clinical and Laboratory Standards Institute. Performance standards for Antimicrobial susceptibility testing; CLSI document M100-S26. $26^{\text {th }}$ ed. CLSI, Wayne. Pennsylvania USA. 2016;36(1).

9. Manish Suthar, Saniya Gupta, Suhail Bukhari, Venkatesh Ponemone. Treatment of chronic non-healing ulcers using autologous platelet rich plasma: a case series. J Biomed Sci. 2017;24(16).

10. Shubhangi Vinayak Agale. "Chronic leg ulcers; Epidemiology, Aetiopathogenesis, and Management. Ulcers 2013; 2013():

11. V. K. Shukla, M A Anssari, S K Gupta. Wound healing research; a perspective from India. Internationa Journal of Lower Extremity Wounds. 2005;4(1):7-8.

12. P K Sarkar, S Ballantyne. Management of leg ulcers. Postgraduate Medical journal 2000; 76(901): 674-682.

13. M.C. Moloney, P. Grace. Undersatanding the underlying causes of chronic leg ulceration. Journal of wound care. 2004;13(6):215-218.

14. R. S. Howell-Jones, M. J. Wilson, K. E. Hill, A. J. Howard, P. E. Price, D. W. Thomas. A review of the microbiology, antibiotic usage and resistance in chronic skin wound. Journal of Antimicrobial Chemotherapy. 2005;55(2):143-149.

15. George Han, Roger Ceilley. Chronic Wound Healing: A Review of Current Management and Treatments. $A d v$ Ther. 2017;34(3):599-610.

16. Trengove NJ, Stacey MC, McGechie DF, Mata S. Qualitative bacteriology and leg ulcer healing. J Wound Care. 1996;5(6):277-80.

17. Thomson, P. D, D. J. Smith. What is infection?. Am. J. Surg. 1994;167(1A):7S-11S.

18. Lawrence, J. C. The bacteriology of burns. J. Hosp. Infect 1985; 6(2):3-17.

19. Heggers J.P. Defining infection in chronic wounds: methodology. An historical review of the quantitative assessment of microbial flora in wounds. $J$. Wound Care 1998;7():452-456.

20. Halcón L, Milkus K. Staphylococcus aureus and Wounds: a Review of Tea Tree Oil as a Promising Antimicrobial. American Journal of Infection Control. 2004; 32(7): 402-8.

21. Hansson, C., Hoborn, J., Mo "ller, A. The microbial flora in venous leg ulcers without clinical signs of infection. Acta Dermato-Venereologica. 1995;75(24-30).

22. Frankel YM, Melendez JH, Wang N, Price LB, Zenilman JM, Lazarus GS. Defining Wound Microbial Flora: Molecular Microbiology Opening New Horizons. Arch Dermatol.2009;145(10):1193-1195
23. Colsky, A. S., Kirsner, R. S. \&Kerdel, F. A. Analysis of antibiotic susceptibilities of skin wound flora in hospitalized dermatology patients. The crisis of antibiotic resistance has come to the surface. Archives of Dermatology 1998; 134(): 1006-9.

24. Tentolouris, N., Jude, E. B., Smirnof, I. Methicillin resistant Staphylococcus aureus: an increasing problem in a diabetic foot clinic. Diabetic Medicine. 1999; 16():76771.

25. Ge, Y., MacDonald, D., Hait, H. Microbiological profile of infected diabetic foot ulcers. Diabetic Medicine 2002; 19(): 1032-5.

26. Moremi, N., Mushi, M. F., Fidelis, M., Chalya, P., Mirambo, M., \&Mshana, S. E. Predominance of multiresistant gram-negative bacteria colonizing chronic lower limb ulcers (CLLUs) at Bugando Medical Center. BMC Research Notes. 2014;7():211.

27. Mohammad Zubair, Abida Malik, Jamal Ahmad. Microbiology of diabetic foot ulcer with special reference to ESBL infections. American Journal of Clinical and Experimental Medicine. 2015; 3(1):6-23.

28. Mathur P, Tatman A, Das B, Dhavan B. Prevalence of ESBL gram negative bacteria in a tertiary care hospital. Indian J Med Microbiol. 2002;115:153-157.

29. Kumar MS, Lakshmi V, Rajagopalan R. Occurrence of extended spectrum beta lactamases among Enterobacteriaceaespp isolated at a tertiary care institute. Indian J Med Microbiol. 2006;24(3):208-11.

30. Umadevi S, Kumar S, Joseph NM, Easow JM, Kandhakumari G, Srirangaraj S, Raj S, Stephen S. Microbiological study of diabetic foot infections. Indian Journal of Medical Specialities. 2011;2(1):12-17.

31. Citron DM, Goldstein EJC, Merriam CV, Lipsky BA, Abtamson MA. Bacteriology of moderate-to-severe Diabetic foot infections and in vitro activity of antimicrobial agents. J. Clin Microbio. 2006;45(9):28192829.

32. Murugan. S, R. Bakkiya Lakshmi, P.Uma Devi and K.R. Mani (). Prevalence and Antimicrobial Susceptibility pattern of Metallo beta lactamase producing Pseudomonas aeruginosa in Diabetic Foot Infection. International Journal of Microbiological Research. 2010;1(3):123-128.

33. Wilson R. Upward trend in acute anaphylaxis continued in 1998-9. British Medical Journal. 2000;321, 1021.

34. Anusha Gopinathan, Chiranjay Mukhopadhyay, Vandana K. E. Characterization of antimicrobial resistance mechanisms of multidrug resistant Gram negative bacterial wound infections and their clinical epidemiology from a tertiary care hospital in Karnataka. India Int J Res Med Sci. 2017;5(3):824-828.

35. Aerden D, Bosmans I, Skin grafting the contaminated wound bed; reassessing the role of pre-operative swab $J$ wound care. 2013;22: 85-9.

36. Ryan J. Donegan. An overview of factors maximizing successful split thickness skin grafting in diabetic wounds. Diabetic Foot \& Ankle. 2014;5:24769.

How to cite this article: Vanaja R, S Geetha Banu. Role of semi-quantitative bacteriological culture in management of chronic wound infections. Indian $\mathrm{J}$ Microbiol Res. 2018;5(3):398-403. 